\title{
ЭКСПОРТ КАК СПОСОБ РАСКРЫТИЯ ПРИРОДНО-ЭКОНОМИЧЕСКОГО ПОТЕНЦИАЛА ПРОИЗВОДСТВА ЗЕРНА В РОССИИ
}

\author{
(c) 2019 Зюкин Данил Алексеевич \\ кандидат экономических наук \\ Курская Государственная сельскохозяйственная академия имени И.И. Иванова, Россия, Курск \\ E-mail: nightingale46@rambler.ru
}

(c) 2019 Соловьева Татьяна Николаевна

кандидат экономических наук, профессор

Курская Государственная сельскохозяйственная академия имени И.И. Иванова, Россия, Курск

E-mail: SolT7370@yandex.ru

В статье показано, что экспорт является эффективным инструментом санации российского зернового рынка в условиях динамичного наращивания урожаев зерновых культур. Поэтому экспорт представляется как основной стимул увеличения валовых сборов, позволяющим активизировать инновационные факторы реализации природно-экономического потенциала зернового хозяйства России. В исследовании предлагается среди инструментов в модели управления процессами экспорта зерна и зернового баланса в стране опираться на методы рыночного регулирования, создающие условия развития производственно-логистической инфраструктуры и возделывания зерна на интенсивной основе.

Ключевые слова: зернопродуктовый подкомплекс, зерновое хозяйство, экспорт зерна, зерновой рынок, управление зерновым балансом, модель регулирования экспортной деятельности.

Зерновое хозяйство - важный элемент зернопродуктового подкомплекса АПК, поэтому от возможностей наращивания объемов и повышения эффективности производства зерна зависит благополучие функционирования всей воспроизводственной цепочки. В условиях динамичного роста урожаев зерна внутренний рынок не может создать достаточный спрос, чтобы стимулировать дальнейший рост валовых сборов зерновых. Поэтому на данном этапе экспорт зерна очень важен для устойчивого функционирования зернового рынка и создания благоприятной ценовой конъюнктуры для его производства, так как это позволяет устранять излишки с внутреннего рынка, создавая стимул к дальнейшему наращиванию урожаев зерновых, в том числе за счет инновационных факторов.

С 2014 года, когда урожаи зерна стабильно стали превышать 100 млн. т, актуальность поиска новых рынков сбыта возросла. Именно за счет экспорта удалось обеспечить дополнительный спрос на возросшие урожаи, объемы которого увеличились почти в 3 раза - с 19 млн. т до почти 55 млн. т зерна. В то же время внутренний спрос вырос на 11,4 млн. т, что безусловно также характеризует развитие зернопродуктового подкомплекса АПК. Однако для реализации природно-экономического потенциала зернового хозяйства экспорт стал более важным элементом, размеры которого теперь даже превышают объемы переработки на муку, крупу, комбикорма и другие цели (таблица 1).

В качестве игрока на мировом рынке зерна Россия следует считать с 2002 года, однако стабильным экспортером Россия стала с сезона 2006-2007 годов (рисунок 1). С 2014 года объемы экспортных поставок вышли на новый уровень, поставив новые вызовы имеющейся логистической инфраструктуре. Только за последнюю пятилетку экспорт вырос на 35,8 млн. т, а его география теперь включает страны Южной Африки и Юго-Восточной Азии, что предопределяет развитие портовой инфраструктуры.

Основными регионами, работающими на экспорт зерновых культур в России, по итогам 2016-2018 гг. являются: Ростовская область, перехватившая лидерство у Краснодарского края, позиции которого сильно пострадали в кризис 2015 г., и Москва, не являющаяся прямым производителем, но выступающая в качестве площадки регистрации крупнейших российских экспортеров, имеющих поля в основных зерно-

* Статья подготовлена при финансовой поддержке РФФИ в рамках научного проекта № 18-310-00211 
Таблица 1. Баланс зерна в России в 2013-2018 гг., млн. т

\begin{tabular}{|c|c|c|c|c|c|c|c|}
\hline \multirow{2}{*}{ Показатель } & \multicolumn{6}{|c|}{ Годы } & \multirow{2}{*}{ Прирост,\% } \\
\hline & 2013 & 2014 & 2015 & 2016 & 2017 & 2018 & \\
\hline Валовой сбор & 92,4 & 105,3 & 104,8 & 120,7 & 135,4 & 113,3 & 22,6 \\
\hline Импорт & 1,5 & 0,9 & 0,8 & 1,0 & 0,7 & 0,6 & $-60,0$ \\
\hline Производственное потребление & 20,0 & 21,0 & 20,9 & 22,4 & 23,5 & 23,4 & 17,0 \\
\hline на семена & 10,4 & 10,9 & 10,7 & 11,3 & 11,4 & 11,1 & 6,7 \\
\hline на корм скоту и птице & 9,6 & 10,1 & 10,2 & 11,1 & 12,1 & 12,3 & 28,1 \\
\hline $\begin{array}{l}\text { Переработано на муку, крупу, } \\
\text { комбикорма и другие цели }\end{array}$ & 44,5 & 46,4 & 48,2 & 51,7 & 56,5 & 52,5 & 18,0 \\
\hline Потери & 1,2 & 1,0 & 1,1 & 1,2 & 1,2 & 1,2 & 0,0 \\
\hline Экспорт & 19,0 & 30,1 & 30,7 & 33,9 & 43,3 & 54,8 & 188,4 \\
\hline Личное потребление & 0,1 & 0,1 & 0,1 & 0,1 & 0,1 & 0,1 & 0,0 \\
\hline
\end{tabular}

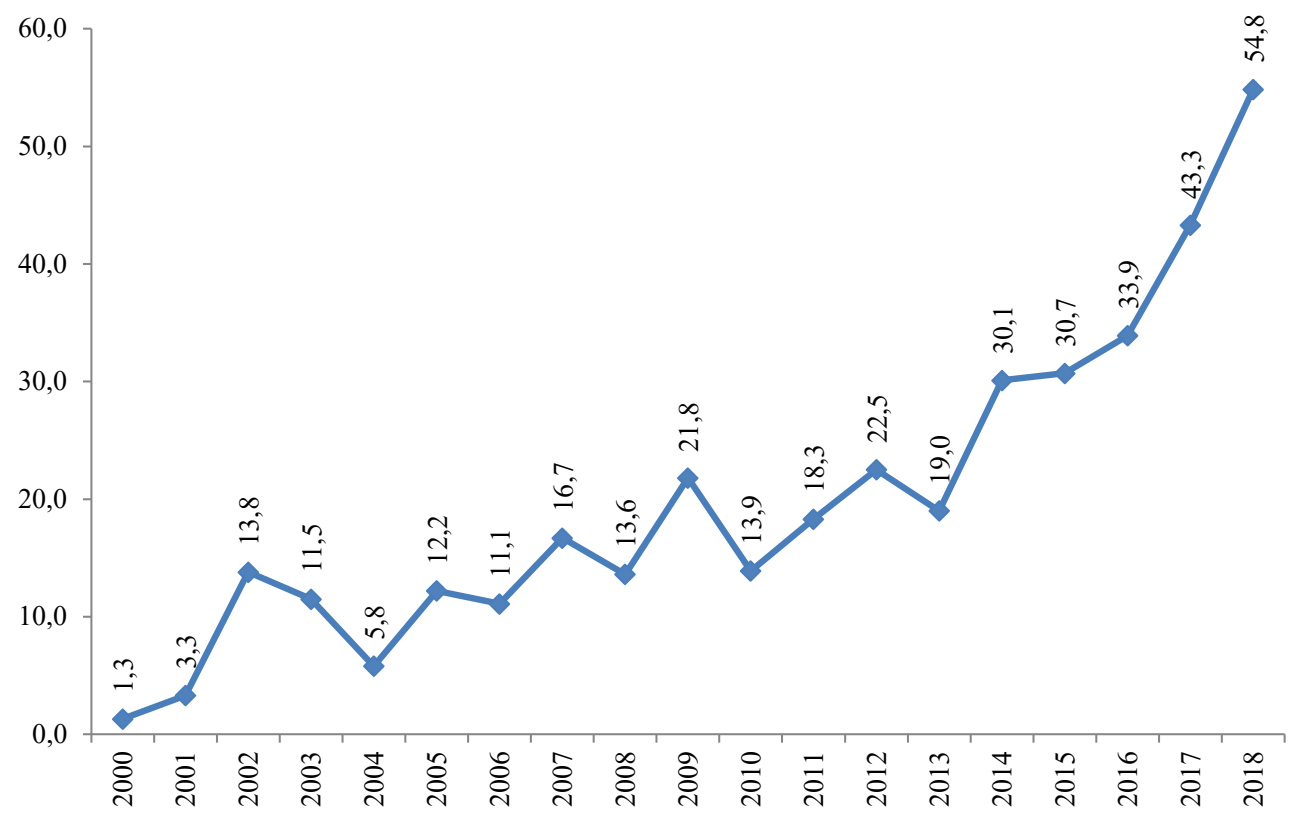

Рисунок 1. Динамика экспорта российского зерна в 2000-2018 гг., млн. т

вых житницах страны. На долю этих регионов приходится около 75\% всего зернового экспорта России [10]. По сравнению с Краснодарским краем, чья доля среди экспортеров занимает почти 30\%, Воронежская область, занимающая чуть менее 5\% в структуре экспорта зерновых, находится на четвертой позиции. Как ни странно, пятая и шестая позиции с долями порядка 2,5\% приходится на Санкт-Петербург и Калининград, где совершенно очевиден факт перекупки, поскольку регионы не являются прямыми производителями. Все остальные регионы, работающие на экспорт зерновых, занимают в общей структуре менее $1 \%$.

Условно все страны, импортирующие наибо- лее значимые объемы зерна из России, можно разделить территориально на четыре зоны, пути транспортировки из России к которым имеют различную степень протяженности (рисунок 2). Развитие российской портовой инфраструктуры в этом вопросе имеет исключительную важность, что обусловлено особенностями доставки российского зерна до конечного потребителя. На данном этапе за исключением Ирана и Азербайджана поставки осуществляются через порты АЧБ (Азово-Черноморского бассейна). В перспективе дальневосточное направление смогло бы упростить доставку до стран Тихоокеанского бассейна, в первую очередь, для Филиппин и Вьетнама, уже являющихся крупными 


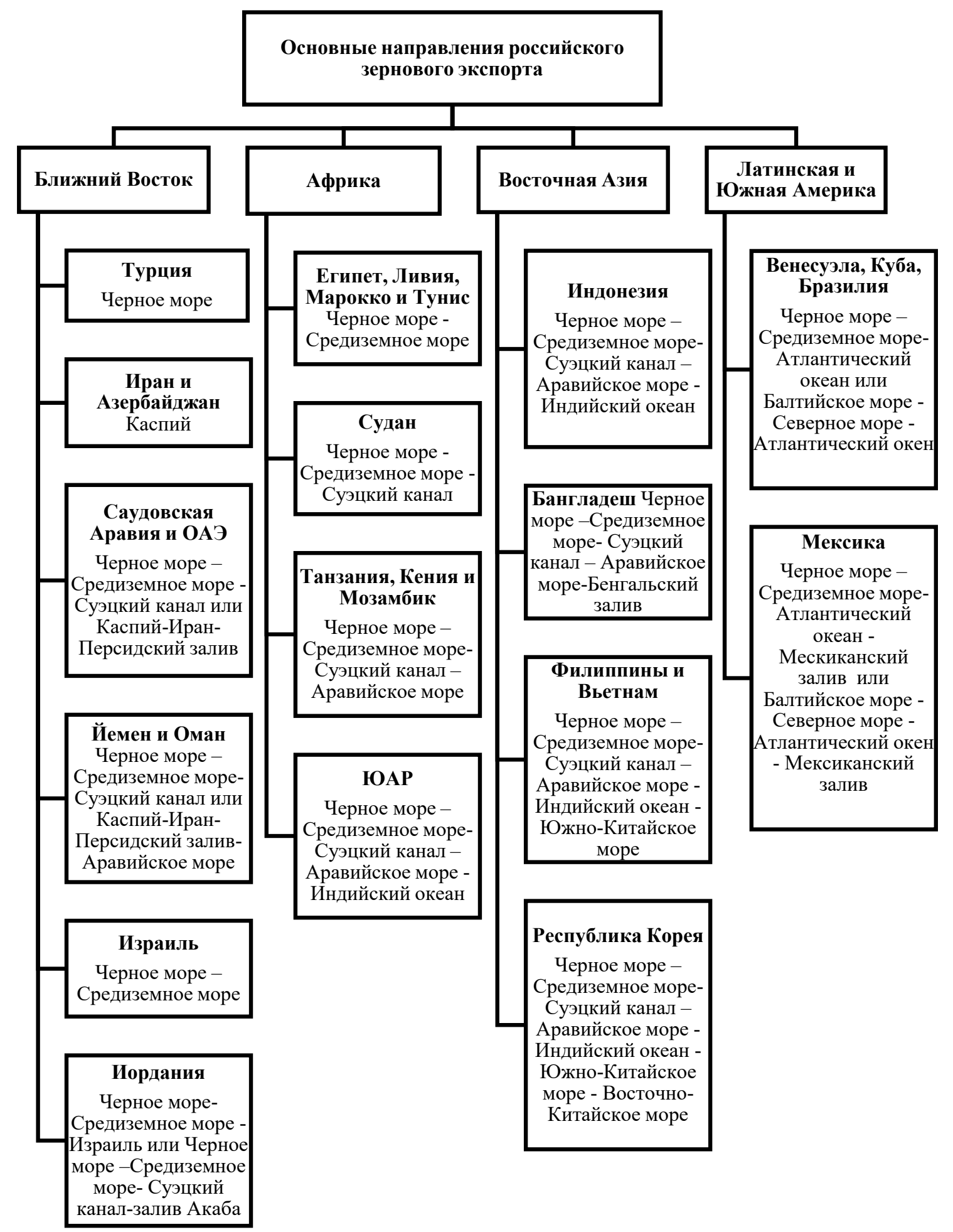

Рисунок 2. Основные направления экспорта российского зерна 
импортерами российского зерна. Это позволит лучше задействовать природно-экономический потенциал восточно-сибирских регионов России за счет экспорта, которые на данном этапе ориентируются на вывоз зерна через порты АЧБ, что существенно увеличивают путь и время поставки.

Как отмечает Олимова Т.О. [1], полноценная эксплуатация транспортного коридора «Север-Юг», через который планируется осуществлять поставки из стран Балтии в Индию через Иран, приведет к уменьшению расстояния перевозок более чем в два раза и снижению стоимости контейнерных перевозок. Для России, как отмечает автор, существенный прорыв в развитии поставок зерна в Иранско-Азербайджанском направлении произойдет с началом полноценной эксплуатации Западного направления транспортного коридора. С вводом в эксплуатацию Западного коридора поставки зерна в Иранском направлении будут практически полностью происходить по железнодорожному сообщению, что, с одной стороны, позволит увеличить их объемы за счет прямого выхода к портам Персидского залива, а с другой - удешевит логистические затраты в этом направлении на $30-35 \%$.

Однако для всех остальных крупных импортеров российского зерна путь к наращиванию поставок за счет улучшения логистических каналов сбыта лежит через развитие портовой инфраструктуры, в особенности глубоководных терминалов. Например, Египет, являясь крупнейший импортер российского зерна, 83,7\% закупленного объема в сезоне 2018/2019 гг. по- лучил через глубоководные порты АЧБ. Сейчас рынки Юго-Восточной Азии и Африки показывают рост спроса на российское зерно: прирост поставок во Вьетнам превысил 2,5 млн. т; Индонезия, Бангладеш, Филиппины, Судан, Нигерия увеличили закупки на 1 млн. т и более (таблица 2). При этом все основные покупатели российского зерна, за исключением Турции, получили через глубоководные порты АЧБ более $60 \%$ от закупленных объемов, что определяет необходимость развития логистической и портовой инфраструктуры, обеспечивающей эффективную работу глубоководных портов АЧБ [2].

Вместе с рекордными поставками зерна, позволившим сделать Россию одним из главных игроков на мировом рынке, нужно отметить сравнительно низкие экспортные цены при невысоком качестве зерна и высокий уровень логистических и производственных затрат. В связи с этим Алтухов А.И. [3] отмечает, что дальнейшие перспективы наращивания экспортных поставок зерна в большей степени будут зависеть от качества экспортируемого зерна, а не только от его количества. Например, в современных реалиях для России открывается перспектива освоения рынков Латинской и Южной Америки, которые в силу национальных особенностей в большей степени нуждаются в кукурузе. Конкурировать на этих рынках с Аргентиной, США и Канадой, расположенных более близко территориально, России будет возможно исключительно за счет напряженного характера отношений латиноамериканских и южноамериканских стран с США и придерживающихся с ними солидарности в вопросах внешней политики странами (Ев-

Таблица 2. Динамика экспорта российского зерна по крупнейшим импортерам в 2014-2018 гг., тыс. т.

\begin{tabular}{|l|c|c|c|c|c|c|}
\hline \multicolumn{1}{|c|}{ Страна } & 2014 г. & 2015 г. & 2016 г. & 2017 г. & 2018 г. & Прирост, тыс. т \\
\hline Египет & 4079 & 4585 & 5893 & 7843 & 9592 & 5513,0 \\
\hline Турция & 5791 & 4698 & 3691 & 5026 & 6837 & 1046,0 \\
\hline Вьетнам & 15 & 0 & 130 & 1688 & 2592 & 2577,0 \\
\hline Иран & 2249 & 2301 & 1899 & 2172 & 2565 & 316,0 \\
\hline Судан & 877 & 356 & 860 & 1455 & 2149 & 1272,0 \\
\hline Саудовская Аравия & 1767 & 3000 & 1392 & 1627 & 2111 & 344,0 \\
\hline Нигерия & 710 & 878 & 1412 & 1386 & 1975 & 1265,0 \\
\hline Бангладеш & 195 & 892 & 1912 & 1923 & 1863 & 1668,0 \\
\hline Ливан & 318 & 498 & 1237 & 1434 & 1395 & 1077,0 \\
\hline Индонезия & 228 & 233 & 174 & 1184 & 1374 & 1146,0 \\
\hline Филиппины & 51 & 0 & 16 & 156 & 1023 & 972,0 \\
\hline Иемен & 984 & 680 & 889 & 1435 & 1343 & 359,0 \\
\hline
\end{tabular}


ропейский союз, Канада, Австралия).

Другим приоритетным моментом, определяющим стратегические перспективы дальнейшего наращивания присутствия России на мировом рынке, является соответствие таким задачам логистической инфраструктуры. Решение такого вопроса лежит в плоскости государственного управления, потому что бизнес реализовывать крупные инфраструктурные проекты в условиях плохого инвестиционного климата в стране не очень заинтересован или даже не способен. К сохранению регулирующей роли государства в организации экспорта обязывает высокая роль зерна как продукта в обеспечении продовольственной безопасности и реализации программы импортозамещения. Однако ограничиваться следует только инструментами управления зерновым балансом страны, за счет которых будут создаваться условия, активизирующие и благоприятствующие экспортной активности, за исключением случаев форс-мажора, например, аномальной засухи лета 2010 года [4].

K основополагающим элементам организации экспорта зерновых, на которые следует воздействовать инструментами регулирования, мы относим 5 элементов [5]:

- повышение эффективности функционирования и организации проведения системы государственных закупок;

- совершенствование транспортно-логистической цепи перевозки зерна внутри страны и на экспорт;

- создание системы информационного обеспечения зернового рынка;

- улучшение организации торговли зерном;

- совершенствование нормативно-правовой базы государственного регулирования и поддержки развития зернового хозяйства.

Необходимость совершенствования модели управления процессами экспорта зерна определяется наличием совокупности недостатков и проблем, снижающих его эффективность и предопределяющих несправедливое распределение доходов не в пользу непосредственных производителей зерна. К таковым относится устаревшая инфраструктура хранения зерна, неэффективная система железнодорожной логистики, недостаток мощностей по перевалке зерна в портах, которые дополняют сложности и проблемы самого зернового хозяйства, определяющие неустойчивость результатов урожая, что, соответственно, сказывается на стабильности объемов экспорта. В условиях медленного роста спроса на зерно на внутреннем рынке страны как минимум в ближайшие годы именно экспорт будет являться основным стимулом увеличения валовых сборов, позволяющим активизировать инновационные факторы реализации природно-экономического потенциала зернового хозяйства.

Среди инструментов, включенных в модель управления процессами экспорта зерна, следует делать опору на рыночных методах регулирования, направленных на стимулирование инвестиционной активности бизнес-единиц на всех этапах воспроизводственной цепочки зернопродуктового подкомплекса АПК, доступности и повышения эффективности экспорта зерна для непосредственных зернопроизводителей. Прямое участие государства в экспорте как показывает практика менее эффективно, поэтому роль государства должна быть именно в создании благоприятных условий для инновационного пути развития зернопродуктового подкомплекса, улучшения производственно-логистической инфраструктуры, совершенствование административной и юридической поддержки и маркетинговое продвижение и защита российских экспортеров.

\section{Библиографический список}

1. Олимова Т.О.Специфика логистической деятельности в агропромышленном комплексе (на примере экспорта зерна) // Молодой ученый. 2017. № 3(137). С. 380-385.

2. Зюкин Д.А., Солошенко Р.В. Улучшение транспортно-логистической инфраструктуры как основа повышения эффективности и диверсификации экспорта российского зерна // Вестник Курской государственной сельскохозяйственной академии. 2019. № 7. С. 141-147.

3. Алтухов А.И. Экспорт российского зерна: проблемы и пути их решения // Никоновские чтения. 2017 . № 22. С. 134-136.

4. Зюкин Д.А. Особенности и значимость зернопродуктового подкомплекса АПК как обоснование необходимости разработки стратегии его развития // Вопросы социально-экономического развития регионов. 2018. № 2 (5). С. 11-19.

5. Зюкин Д.А. Развитие экспортного потенциала зернового хозяйства России // Экономика сельскохозяйственных и перерабатывающих предприятий. 2019. № 1. С. 58-61. 